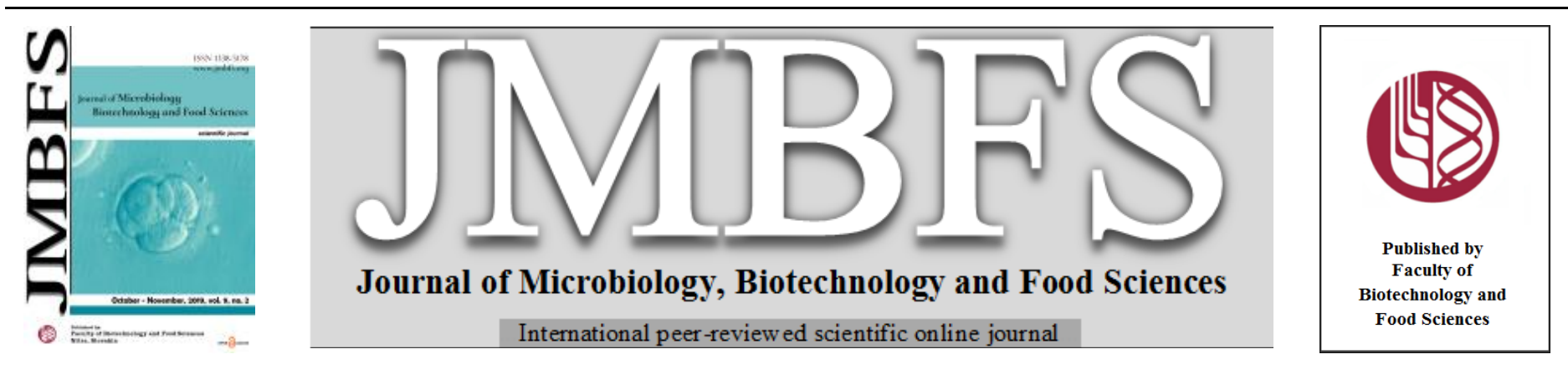

\title{
REDUCTION OF OIL UPTAKE FROM POTATO FENCH FRIES BY PLASTICISER SHELLAC AND ULTRASOUND TECHNOLOGY
}

\author{
Devashree Kulkarni ${ }^{1 \xi}$, Soumyasudha Panda ${ }^{1 \xi}$, Sachin K. Sonawane, Ashish S. Dabade ${ }^{*}$ \\ Address(es): \\ ${ }^{I}$ School of Biotechnology and Bioinformatics, D.Y. Patil Deemed to be University, Food Science and Technology, CBD Belapur, Navi Mumbai, India.
}

*Corresponding author: ashish.dabade@dypatil.edu

doi: 10.15414/jmbfs.2020.9.4.813-815

\section{ARTICLE INFO}

Received 22. 5. 2018

Revised 16.9. 2019

Accepted 27. 9. 2019

Published 3. 2. 2020

Regular article

open $\partial_{\text {aCcESS }}$

\begin{abstract}
Edible lac resin, shellac in different concentrations was used as a coating agent to reduce the oil uptake in deep-fried potato fries. The coating formulation was carried out by Shellac and D-Sorbitol. Shellac used in the concentrations $0 \%, 1 \%, 2 \%, 3 \%, 4 \%$ and $5 \%$ in combination with $0.25 \%$ D-sorbitol. Further coated samples were treated with ultrasonication for 5 minute and 10 minutes at $50 \mathrm{~Hz}$. Potato fries coated with shellac and ultrasonicated were deep fried and analyzed for oil uptake, moisture content, color and sensory analysis. The oil content and moisture content of deep fried potato fries were determined using standard AOAC method, the colour analysis was carried out by software-based application and sensory analysis was carried out by a 9 point hedonic scale by 30 untrained panelists. With the increase in the concentration of shellac, the oil uptake by potato fries significantly reduced showing the highest reduction of $54.24 \%$ in $5 \%$ shellac coated potato fries. Potato fries coated with 5\% shellac and ultrasonicated for 5 minutes showed $55.07 \%$ reduction whereas at 10 minutes, it showes reduction of $57.87 \%$.
\end{abstract}

\section{INTRODUCTION}

Over the last few decades, rapid economic development, mechanization and market globalization across the world have led to enormous changes in diets and lifestyles. The need for a longer shelf life led to the need for the modification of natural forms of foods. Frying is a very old method of cooking and was used in the Mediterranean countries many centuries ago (Gadiraju et al., 2015).

Frying is a mass transfer method in which heat and mass transfer take place to carry out desirable changes in the product. Deep frying allows the expanding of food products because of its distinctive quality attributes, including the formation of a dual structure of the fried product, and the development of distinctive tempting color, flavor, aroma and textural attributes (Funami et al., 1999).

The uptake of fat by the fried potatoes largely takes place during the cooling process, after the removal of the samples from the oil medium. Oil that is adhered to the surface migrates into the internal core due to changes in potato microstructure which have taken place during frying. Fried potato products thus have a high caloric value which increases during the deep-fat frying process. Excessive consumption of energy-dense foods which high in fat, mostly saturated fat can lead to weight gain, obesity and pose an increased risk of NonCommunicable Diseases (NCDs). Dietary fats play an important role in the development of cardiovascular diseases. Hence, the focus of dietary guidelines in the last few decades is recommendations of reduced total fat (Gadiraju et al., 2015).

Chronic non-communicable diseases (NCDs), like coronary heart disease (CHD), stroke, hypertension, diabetes mellitus and obesity, are major causes of mortality and morbidity worldwide (Nishida et al., 2004b). Increasing awareness of the health issues linked to the consumption of fried products has led to the need to develop and process food products and fried products which are low in oil content. One of the leading risk factors for death and disability in the United States is suboptimal diet quality, which in 2010 was associated with 678,000 annual deaths (Go et al., 2014a). Most of the NCD deaths are due to cardiovascular diseases which accounts for 17.7 million people annually and diabetes which accounts for 1.6 million (Go et al., 2014b).

An edible film onto the potato fries to be fried is a thin layer formed on food. It covers the food product totally acting as a layer of a barrier for more oil to seep into the product. Many edible films are used to reduce the uptake of oil in different foods. Hydrocolloids like carboxymethyl cellulose was proven to reduce the fat uptake in deep fat fried paneer (Sharma, Singhal, Kulkarni, \& Gholap, 1999a), edible coating of sunflower head pectin was also proven to reduce the uptake of fats in fried potato chips (Nishida, Uauy, Kumanyika, \& Shetty, 2004a), Guar gum with sorbitol was also studied to reduce the fat absorption in French fries (Jia, Fan, Li, Duan, \& Fan, 2017a) and many more edible coating are studied to reduce the fat uptake.

Duffy ( U.S. Patent No. 5202137A, 1993) suggested the use of shellac as means of a barrier to oil uptake. Shellac is a purified form of the natural resin lac which is secretion of the insect Kerria Lacca, also called as the lac insect. This secretion hardens and a hardened resin i.e. shellac is obtained. Shellac is non-toxic, physiologically harmless and therefore listed as generally recognized as safe (GRAS) by the FDA (Jia, Fan, Li, Duan, \& Fan, 2017b). Shellac can be used as a component for coating in contact with foods (FDA 21 CFR 175.300). According to CODEX bleached shellac (E 904) can be added at GMP level in vegetables which are to be surface coated. An ultrasound treatment applied to cooking with oil which provides better quality of fried products with reduction of energy consumpation (Rana et al., 2017). The key application of ultrasound is obsrved in processing, preservation and safety. The promising results in reduction of oil take is given by ultrasound technology due to its high dehydration efficiency (Dehghannya et al., 2016).

The objective of this study was to evaluate the performance of plasticised lac resin, Shellac as an edible coating film on potato fries and ultrasonicating the potato fries in the reduction of oil uptake and how it influences the oil uptake with different concentrations of shellac and different time of ultrasonication technology.

\section{MATERIAL AND METHODS}

\section{Materials}

McCain French Fries (Frozen), as well as Gemini refined Sunflower oil, was brought from the local markets of Navi Mumbai. Pharma grade shellac was supplied by Adhya International Pvt. Ltd. D-Sorbitol powder (14281: SRL), Petroleum Ether (LR 60-80: SDFINE) and 99.9\% Ethanol were also bought. Deep Fryer (Skyline Fryer- VTL-5424). Ultrasonicator.

\section{Sample Preparation}

Frozen potato fries of the brand McCain were used as the sample product for this research. This packet of frozen French fries was stored at $-18^{\circ} \mathrm{C}$. Pre-treatment 
was done in frozen conditions only. No thawing of the frozen fries was allowed to happen. The potato fries were processed as per instruction on the label.

\section{Coating Solution Preparation}

For coating formulation, five concentrations of $1 \%, 2 \%, 3 \%, 4 \%$ and $5 \%$ shellac were made in $99.9 \%$ pure ethanol (w/v). A solution of each concentration was stirred on a magnetic stirrer at room temperature for 5 minutes till the shellac was totally solubilized in the ethanol added. The shellac solution of each concentration was filtered using a muslin cloth to get a clear solution without any suspended particles. $0.25 \%$ D- Sorbitol solution was prepared in distilled water. These were also stirred on a magnetic stirrer at room temperature for 5 minutes till the Sorbitol was completely solubilized in the distilled water. Each time fresh Sorbitol solution was prepared for different concentrations.

\section{Coating Application}

The potato strips were dipped for 30 seconds in the shellac solution first, followed by dipping the same in $0.25 \%$ Sorbitol solution for 10 seconds. The potato strips after these treatments were air dried for another 30 seconds. Ethanol was allowed to evaporate to ensure the formation of proper plasticized shellac coating on the potato strips.

\section{Ultrasound Treatment}

The samples were ultrasonicated after being coated by plasticized shellac for 5 minutes and 10 minutes at the frequency of $50 \mathrm{~Hz}$ and the relationship of ultrasonication time with fat uptake by potato fries was calculated. This was also compared with the samples coated with plasticized shellac followed by frying without any ultrasonication treatment.

\section{Deep Frying and Frying Conditions}

The coated and ultrasonicated potato strips were then deep fried in electronic deep fryer filled with 2 liters of oil. The time-temperature combination for frying was followed as per the instruction is given on the packet of McCain Potato Fries. Fries were fried at $175 \pm 2{ }^{\circ} \mathrm{C}$ for 3 minutes in an electric deep fryer. To monitor the temperature a cooking thermometer was used. After 3 minutes of frying, the potato fries were removed, drained properly by vigorously shaking the frying basket. Oil was changed after every 3 cycles of frying. A control sample was fried without any of the coating pre-treatment given to it. All the experiments were performed in triplicate to get an accuracy in results.

\section{Fat Uptake Determination}

The fat/ oil content was determined by standard AOAC 946.16 method using Soxhlet apparatus using petroleum ether as solvent. Solvent extraction was done for 16 hours at $70^{\circ} \mathrm{C}$ trying to keep the atmospheric conditions similar to samples of similar concentrations. After completion of the prescribed cycles for 16 hours, the fat and moisture mixture obtained in the distillation flask which was preweighed was kept in an oven at $105^{\circ} \mathrm{C}$ for 24 hours to let the moisture in it evaporate. This was repeated for all the samples.

\section{Moisture Content Determination}

The moisture content in potato fries was determined by the gravimetric method. For moisture content determination, the potato fries were kept in an oven at $105^{\circ} \mathrm{C}$ for 24 hours till a constant weight is obtained as per AOAC.

\section{Organoleptic Evaluation of Potato Fries}

The sensory evaluation was done by 30-panel members who were semi-trained and technical members who were familiar with the quality of the different type of foods and were able to follow instructions, discriminating differences and communicating their reactions. All the potato fries samples to be tested were presented by identical methods. Attributes like aroma, color, taste, flavor, mouth feel after taste was tested on 9 points hedonic scale ranging from 9= Like extremely to $1=$ Dislike extremely. The average sensory score and standard deviation were calculated for each sample.

\section{Statistical Analysis}

Statistical analysis of samples was carried out by SPSS software module. The one way ANOVA, homogenous subset test was carried out by a statistical method to determine significant diffrencs in availble set of samples for oil reduction.

\section{RESULTS AND DISCUSSION}

\section{Effect of plasticised shellac and ultrasonication on the fat content of potato fries}

From table 1 average fat content of control sample was $31.65 \%$. With the increase in the concentrations of shellac from $1 \%$ to $5 \%$, there was a significan decresed in the fat content that was $31.65 \%$ to $14.49 \%$ which corresponds to 0 to $54.23 \%$ reduction of fat. The $5 \%$ of plasticised shellac shows effective reduction fat content i.e $54.23 \%$.

Table 1 Characterization of deep-fried dough discs with different coating concentrations of plasticized shellac $(\mathrm{n}=3)$

\begin{tabular}{lccc}
\hline Concentrations & \% Fat & \% Fat Reduction & \% Moisture \\
\hline Control & $31.65 \pm 0.49^{\mathrm{e}}$ & $0 \pm 0^{\mathrm{f}}$ & $4.40 \pm 0.54^{\mathrm{c}}$ \\
$1 \%$ & $29.04 \pm 0.24^{\mathrm{d}}$ & $8.23 \pm 0.67^{\mathrm{e}}$ & $3.45 \pm 0.06^{\mathrm{ab}}$ \\
$2 \%$ & $26.27 \pm 0.49^{\mathrm{c}}$ & $16.99 \pm 0.27^{\mathrm{d}}$ & $3.57 \pm 0.40^{\mathrm{abc}}$ \\
$3 \%$ & $24.75 \pm 1.48^{\mathrm{c}}$ & $21.83 \pm 3.47^{\mathrm{c}}$ & $3.90 \pm 0.42^{\mathbf{b c}}$ \\
$4 \%$ & $17.46 \pm 0.90^{\mathrm{b}}$ & $44.85 \pm 1.99^{\mathrm{b}}$ & $3.71 \pm 0.57^{\mathrm{abc}}$ \\
$5 \%$ & $14.49 \pm 1.00^{\mathrm{a}}$ & $54.23 \pm 2.46^{\mathrm{a}}$ & $2.84 \pm 0.59^{\mathrm{a}}$
\end{tabular}

- Mean \pm Standard deviation $\overline{(\mathrm{n}=3)}$. Different letters used in the same column as superscripts indicate significant differences $(\mathrm{p}<0.05)$ between the means

For potato fries treated with plasticised shellac concentration 4 and 5\% with employing ultrasonicated for both 5 minutes shows 46.19 and $55.07 \%$ whereas for $10 \mathrm{~min}$ it shows 49.76 and $57.85 \%$ reduction in fat of potato fries treated which were compartively higher only treated with plasticized shellac and control sample respectively. From table 2, it was clear that as the concentration of plasticized shellac increases which results in the decreses in the fat absorption. Percent reduction of fat showed an inverse relationship with fat percentage; as the fat content of potato fries decreased the percent reduction showed an increase. Subsequently, there was a direct relationship between the concentrations of Shellac and the percent reduction. With an increase in time for which the potato fries were subjected to ultrasonication and increase in concentration, there was a reduction in fat content.

Table 2 Characterization of deep-fried dough discs with different coating concentrations of plasticized shellac and ultrasonicated for 5 minutes

\begin{tabular}{|c|c|c|c|c|c|c|}
\hline Concentrations & & $\begin{array}{l}\text { Ultrasonications } \\
\text { treatment for } 5 \mathrm{~min}\end{array}$ & & & $\begin{array}{l}\text { Ultrasonications } \\
\text { treatment for } 10 \mathrm{~min}\end{array}$ & \\
\hline & Fat content & Fat Reduction (\%) & $\begin{array}{l}\text { Moisture } \\
\text { Content }\end{array}$ & Fat content & Fat Reduction (\%) & Moisture Content \\
\hline Control & $31.65 \pm 0.49^{f}$ & $0 \pm 0^{\mathbf{f}}$ & $4.40 \pm 0.54^{b}$ & $31.65 \pm 0.49^{\mathrm{e}}$ & $0 \pm 0^{\mathbf{e}}$ & $4.40 \pm 0.54^{\mathrm{c}}$ \\
\hline $1 \%$ & $28.29 \pm 0.84^{\mathrm{e}}$ & $10.62 \pm 1.27^{\mathrm{e}}$ & $3.44 \pm 0.29^{\mathrm{a}}$ & $21.74 \pm 1.16^{\mathrm{d}}$ & $31.31 \pm 2.57^{\mathrm{d}}$ & $3.51 \pm 0.40^{\mathrm{ab}}$ \\
\hline $2 \%$ & $24.21 \pm 0.80^{\mathrm{d}}$ & $23.51 \pm 1.35^{\mathrm{d}}$ & $3.54 \pm 0.22^{\mathrm{a}}$ & $20.74 \pm 0.49^{d}$ & $34.43 \pm 2.57^{d}$ & $3.65 \pm 0.23^{\mathrm{ab}}$ \\
\hline $3 \%$ & $22.39 \pm 1.14^{\mathrm{c}}$ & $29.28 \pm 2.51^{\mathrm{c}}$ & $3.22 \pm 0.41^{\mathrm{a}}$ & $18.57 \pm 0.95^{\mathrm{c}}$ & $41.34 \pm 2.10^{\mathrm{c}}$ & $3.31 \pm 0.18^{\mathrm{a}}$ \\
\hline $4 \%$ & $17.04 \pm 1.32^{\mathbf{b}}$ & $46.19 \pm 3.34^{b}$ & $3.43 \pm 0.23^{\mathrm{a}}$ & $15.91 \pm 1.41^{\mathbf{b}}$ & $49.76 \pm 3.69^{\mathbf{b}}$ & $4.18 \pm 0.50^{\mathbf{b c}}$ \\
\hline $5 \%$ & $14.22 \pm 0.30^{\mathbf{a}}$ & $55.07 \pm 0.26^{\mathbf{a}}$ & $3.65 \pm 0.42^{\mathrm{a}}$ & $13.33 \pm 0.16^{\mathbf{a}}$ & $57.86 \pm 1.16^{\mathrm{a}}$ & $4.13 \pm 0.07^{\mathbf{b c}}$ \\
\hline
\end{tabular}

Mean \pm Standard deviation $(\mathrm{n}=3)$. Different letters used in the same column as superscripts indicate significant differences $(\mathrm{p}<0.05)$ between the means It has been ovserved that the ultrasound facilitates changes in microcompartments of materials. Such changes may lead to hold high amount of water in the microcompartment for fresh ultrasound treated samples (Hu, Li-Chan, Wan, Tian, \& Pan, 2013). The increase in protein density, structural rearranegment which may facilates the the microcapsule numbers as well as surface area to adsorb plastisizer. The encorpoation of more amount of plasticizer inside the structure leads to high water holding capacity of the sturcture. The higher the water holding capacity ultimatly reduces oil absoption capacity.

The moisture content was less in all the treated samples as compared to control sample. The moisture content in control sample was $4.40 \% \pm 0.54$. The sample treated with $5 \%$ plasticised shellac showed least moisture content having an average moisture content of $2.84 \% \pm 0.59$. In potato fries treated with $3 \%$ plasticised shellac and ultrasonicated for 5 minutes, least moisture content of $3.22 \% \pm 0.41$ was observed. In potato fries treated with $3 \%$ plasticised shellac and ultrasonicated for 10 minutes, least moisture content of $3.31 \% \pm 0.18$ was 
observed ( Table 1,2). The similir results were obsereved by Oladejo et al. (2017) which shows the reduction in moisture content and oil uptake by ultrasound technology.

\section{Effect of shellac dosage on Sensory characteristics of potato fries}

From fig 1. The control sample of potato fries were scored highest in appearance, color, taste, flavor, mouth feel, aftertaste, and overall acceptability. The $4 \%$ of shellec treated sample were close to the control sample. The sensory of $4 \%$ of shellec treated sample overlap with $3 \%$ of shellec treated sample.

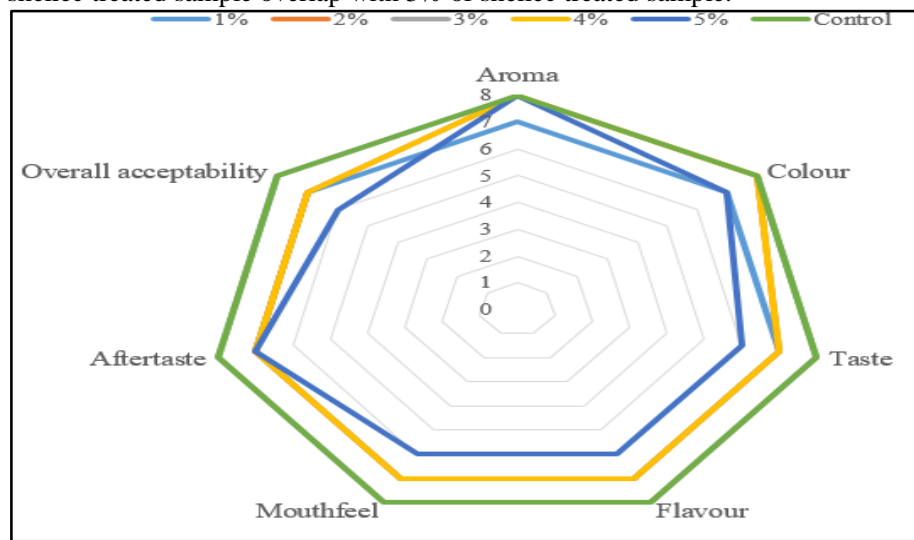

Figure 1 Radar graph for 9-point hedonic scale sensory evaluation of potato fries treated with a plasticised shellac based on appearance, color, taste, flavor, mouth feel, aftertaste, overall acceptability. (The graph of $4 \%$ plasticised shellac merged with control sample)

From fig 2, the sample treated with 5 min ultrasonication in which $4 \%$ of shellec treated sample were closed to control sample. Similar score were observed in the fig 5 . The sensory score given by $4 \%$ were overlapped on $3 \%$ of shellac treated sample in case taste, flavor, mouth feel, and aftertaste (shown in fig 2 and 3)

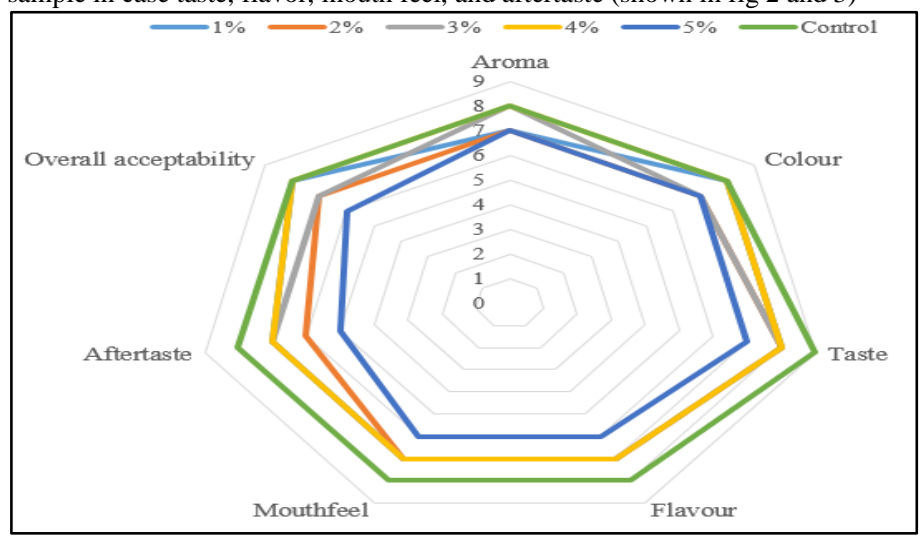

Figure 2 Radar graph for 9-point hedonic scale sensory evaluation of potato fries treated with plasticised shellac and ultrasonicated for 5 minutes based on appearance, color, taste, flavor, mouth feel, aftertaste, overall acceptability. (The graph of $4 \%$ plasticised shellac ultrasonicated for 5 minutes merged with control sample)

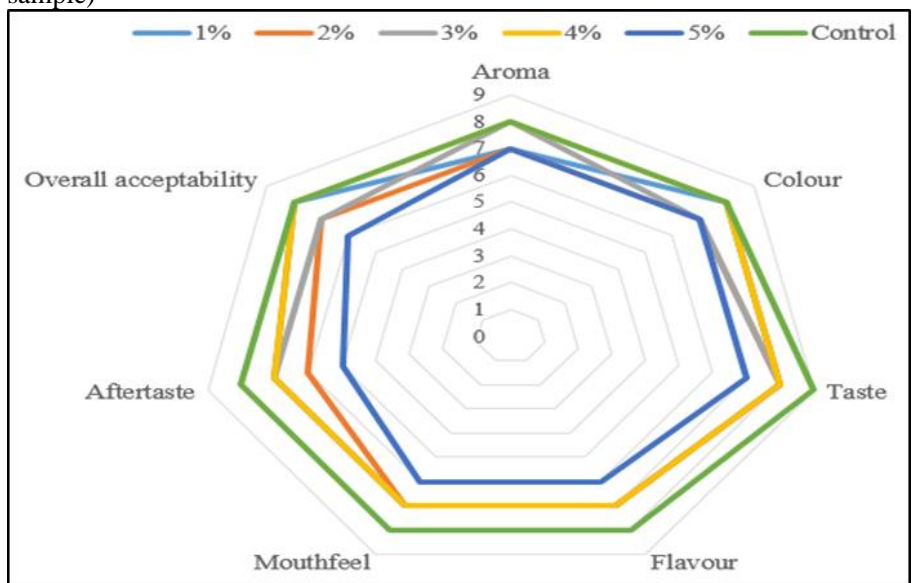

Figure 3 Radar graph for 9-point hedonic scale sensory evaluation of potato fries treated with plasticised shellac and ultrasonicated for 10 minutes based on appearance, color, taste, flavor, mouth feel, aftertaste, overall acceptability. (The graph of $4 \%$ plasticised shellac ultrasonicated for 10 minutes merged with control sample)
Thus from the data obtained from the sensory evaluation of potato fries, it can be said that pre-treatment of potato fries with shellac at $4 \%$ concentration had the best sensorial acceptability, where $3 \%$ concetration were also similar but higher percentage of reduction in fat seen in $4 \%$ concentration.

\section{CONCLUSION}

Plasticised shellac coating formulation showed great mass transfer barrier properties. Plasticised shellac is promisssing additative which helps in reduction of fat. The $4 \%$ concentration of shellac reduces $44 \%$ of fat and furthet it can be reduce by using ultrasnication treatement for 5 and 10 min which show 46 an $49 \%$ reduction respectively. Consumer acceptance was similar to that obtained with the control product since they were not able to distinguish among them. Due to health concern plasticised shellac coating with ultrasonication is promising technology to reduce fat from potato fries or from snack products.

\section{REFERENCES}

Dehghannya, J., Naghavi, E. A., \& Ghanbarzadeh, B. (2016). Frying of potato strips pretreated by ultrasound-assisted air-drying. Journal of Food Processing and Preservation, 40(4), 583-592. https://doi.org/10.1111/jfpp.12636

Funami, T., Funami, M., Tawada, T., \& Nakao, Y. (1999). Decreasing oil uptake of doughnuts during deep-fat frying using curdlan. Journal of Food Science 64(5), 883-888. https://doi.org/10.1111/j.1365-2621.1999.tb15933.x

Gadiraju, T., Patel, Y., Gaziano, J., \& Djoussé, L. (2015). Fried food consumption and cardiovascular health: A review of current evidence. Nutrients, 7(10), 8424-8430. https://doi.org/10.3390/nu7105404

Benjamin, E. J., Blaha, M. J., Chiuve, S. E., Cushman, M., Das, S. R., Deo, R., .. \& Jiménez, M. C. (2017). Heart disease and stroke statistics-2017 update: a report from the American Heart Association. circulation, 135(10), e146-e603. https://doi.org/10.1161/01.cir.0000441139.02102.80

Hu, H., Li-Chan, E. C., Wan, L., Tian, M., \& Pan, S. (2013). The effect of high intensity ultrasonic pre-treatment on the properties of soybean protein isolate ge induced by calcium sulfate. Food Hydrocolloids, 32(2), 303-311. https://doi.org/10.1016/J.FOODHYD.2013.01.016

Jia, B., Fan, D., Li, J., Duan, Z., \& Fan, L. (2017). Effect of guar gum with sorbitol coating on the properties and oil absorption of French fries. International $\begin{array}{llll}\text { journal of molecular } & \text { sciences, } & 18(12), & 2700\end{array}$ https://doi.org/10.3390/ijms18122700

Nishida, C., Uauy, R., Kumanyika, S., \& Shetty, P. (2004). The joint WHO/FAO expert consultation on diet, nutrition and the prevention of chronic diseases: process, product and policy implications. Public health nutrition, 7(1a), 245-250. https://doi.org/10.1079/PHN2003592

Oladejo, A. O., Ma, H., Qu, W., Zhou, C., Wu, B., Yang, X., \& Onwude, D. I. (2017). Effects of ultrasound pretreatments on the kinetics of moisture loss and oil uptake during deep fat frying of sweet potato (Ipomea batatas). Innovative food science \& emerging technologies, 43, 7-17. https://doi.org/10.1016/j.ifset.2017.07.019

Sharma, H. K., Singhal, R. S., Kulkarni, P. R., \& Gholap, A. S. (1999). Carboxymethyl cellulose (CMC) as an additive for oil reduction in deep-fat fried paneer. International journal of dairy technology, 52(3), 92-94. https://doi.org/10.1111/j.1471-0307.1999.tb02079.x 